\title{
ИНДИЯ В ПОИСКЕ СМЫСЛА СУЩЕСТВОВАНИЯ: ФИЛОСОФСКО-КУЛЬТУРОЛОГИЧЕСКИЙ ПОДХОД
}

\section{INDIA IN SEARCH OF THE MEANING OF EXISTENCE: A PHILOSOPHICAL AND CULTURAL APPROACH}

\section{Matvienko}

Summary: India has always sought a rational search for the fact of its existence in space and time. Since ancient times, Indian thought has been continuously caught between fact and illusion, focusing on the phenomenal opposites of matter, life, and mind, and continuing to search for meaning throughout India's long and continuous history. Analyzing this search, you can see how India constantly returns to the theme of synthesis, not just in thought, but in every aspect of life, so it is not surprising that harmony, balance and equilibrium are inherent in the nature of Indian culture.

Keywords: India, Indian philosophy, Indian culture, Varnas, ancient Indian epics, Hindu Scriptures, spiritual synthesis.

\author{
Матвиенко Валентин Викторович \\ К.филол.н., доцент, Российский университет \\ дружбы народов, Москва \\ matvienko-vv@rudn.ru
}

Аннотация: Индия всегда стремилась к рациональному поиску факта своего бытия в пространстве и времени. Индийская мысль с древности непрерывно находилась между фактом и иллюзией, акцентируясь на феноменальных противоположностях материи, жизни и ума, и продолжая поиск смысла на протяжении долгой и непрерывной истории Индии. Анализируя этот поиск, можно заметить, как Индия постоянно возвращается к теме синтеза не просто в мысли, а в каждом аспекте жизни, потому неудивительно, что гармония, баланс и эквилибриум присущи характеру индийской культуры.

Ключевые слова: Индия, индийская философия, индийская культура, варны, древнеиндийские эпосы, священные писания индуизма, духовный синтез.

физиологическое функционирование тела и ума было возведено до высочайшей точки своего значения, а затем генерировано и контролировано.

Хатха йога концентрировалась на функциях тела, что обеспечивало физическое здоровье и энергию, но она также выполняла задачу подготовки индивидуума для более глубоких духовных реализаций. Раджа йога выявляла методы, с помощью которых можно было контролировать сознание, а ум приводить в состояние светлого покоя. Бхакти йога и карма йога были посвящены функциям любви и акции в человеке. Они достигали высочайших уровней сознания посредством любви индивидуальной души к личному Богу и через отрешенную акцию самообладания в жизни [2].

Упанишадская мысль, также называемая ведантой (в буквальном переводе это конечная часть Вед, представляющая апогей ведического видения), контрбалансировала ритуалистическую часть Вед, посвященную значению, символизму и соблюдению ритуалов. Упанишады символизировали новый поиск, где истина ощущалась не как манера ритуализма, а как расследование, не скованное догматическими или эксклюзивными предположениями [3].

Вместе с этим росла и сложная система этики, которая одновременно контролировала и потакала характеру человека, помогая ему лучше играть свою социальную 
роль. «Дхарма» (праведность), «артха» (богатство), «карма» (действие) и «мокша» (спасение) - эти четыре понятия, определяющие цель жизни индийца, имеют богатую подоплеку, указывая на то, что этика предусматривает должное место делу получения удовольствия, достижения богатства и процветания. Именно в этом контексте можно понять, каким образом индийская культура стала воплощать и манифестировать тенденции в сторону богатства материальной жизни с одной стороны и полного отречения от земных благ с другой. Связующим звеном в этой структуре ценностей был ашрам (духовная община, обитель), помогавший человеку на различных стадиях жизни подготовится к своему высочайшему предназначению [3].

Первой такой стадией была брахмачария (безбрачие). Это период получения знаний под руководством гуру (духовного наставника), чьей задачей было больше пробуждать ум, нежели наставлять. Система образования была гибкой, далеко устраненной от сегодняшних образовательных систем, ориентированных на жесткую регламентацию и подчинение правилам. Упор делался на культивацию этических и эстетических качеств в совокупности со строгой самодисциплиной. Целью ее было сотворение идеального и рационального ума как с духовной точки зрения, так и с общеобразовательной. В древней системе образования доминировала концепция идеала. Такое образование готовило человека встречать все превратности судьбы спокойно и с достоинством [4].

Считается, что завершая данную подготовку, индивидуум достигал зрелости, становился мужчиной и был готов играть роль члена общества в грахастья/грихастха ашраме (семейной жизни). Именно здесь проверялись полученная им подготовка, знания и дисциплина, выполнение долга перед семьей, друзьями и обществом. Существует аргумент, что такое теоризирование связывает индивидуума, ограничивая его свободу выбора, и что излишнее увлечение делом достижения целей в жизни лишает ее изюминки. Здесь уместно указать, что древние ясновидцы Индии не пытались регламентировать жизнь таким образом. Они просто предоставляли широкие рамки того, как человек может регулировать свою жизнь, подчеркивая важность каждого момента и фазы, а также радость существования.

Взаимосвязанной с концепцией «ашрама» была система «варны», подчеркивающая социальное положение индивидуума. Позднее эта система дегенерировала в узкую и жесткую систему кастеизма. Тем не менее, какую бы неудачную форму она ни имела в последнее время, первоначально она исходила из самих недр духовности.

Разделение людей по варнам на брахманов (тех, кто познал Брахман (абсолют), кшатриев (воинов/властите- лей), вайшьев (торговцев) и судр/шудр (рабочих и крестьян) было качественным социальным разделением на основе качеств души, как это позднее предлагал Платон. Истина состоит в том, что в каждом человеке вне зависимости от его принадлежности к той или иной варне есть потенциальный Брахман. Некоторые величайшие мудрецы-аскеты, включая авторов «Рамаяны» и «Махабхараты», были низкого происхождения. Такое упорядоченное разделение было предназначено лишь для определения места каждого индивидуума в обществе с тем, чтобы он мог лучше служить Ему, исполняя роль, к которой он больше всего предрасположен по темпераменту. Кастовая система внутри варн была эластичной и гибкой. Основная идея варн заключалась в том, что человек был не роботом, а будущим богом, рожденным расцвести и реализовать свой потенциал, а функция общества - в предоставлении человеку условий для того, чтобы он мог выполнить свое предназначение, исполнив свою индивидуальную и коллективную роль [5].

Данная практическая этика нашла отражение в двух великих эпических повествованиях Индии - «Рамаяне» Валмики и «Махабхарате» Вьясы, ставших частью индийского образа жизни. Они оказали глубокое влияние на мышление людей и широко распространены в песнях, поэзии, драме и других видах искусства. Эпосы полны благородных примеров из жизни святых и правителей, идеалов человеческого поведения и социальных и религиозных наставлений, указывающих обществу путь и сегодня [6].

Вторым образцом великого синтеза индийской мысли после Упанишад является еще один индийский памятник религиозно-философской мысли «Бхагавад-Гита», ставший источником вдохновения для миллионов [7].

На всем протяжении истории пробужденного мышления неизменно задавался вопрос, какова цель жизни и каким образом человек обретает характер и глубину. В индийском мышлении уникальное место занимает буддизм. Несмотря на утверждения, что он не зависим от мышления Упанишад, источником духовности в буддизме являются именно Упанишады. С подтверждением того факта, что состояние нирваны (спасения) и состояние деятельности не противоположны друг другу, буддизм можно считать примером третьего синтеза в духовной истории Индии. В поиске полной трансцедентации Будда отошел от религиозного обскурантизма, в который впало мышление Упанишад, преодолел расовые барьеры, поднявшиеся в его время, и начал движение за утверждение самой сущности Упанишад и Бхагавад-Гиты с новых позиций и в новой терминологии интеллектуального определения и логики [4].

Позднее появились великие философские школы веданты, порожденные видением Ади Шанкарачарьи, 
Мадхавачарьи и Рамануджи, чьи труды, посвященные Брахма Сутрам, содержащим квинтэссенцию мысли Упанишад в 555 афоризмах, стали источниками трех главных потоков мысли веданты. Это адваита веданта Шанкары, философия неквалифицированного монизма, дваита (дуализм) Мадхавачарьи, выступающая за бескомпромиссный монизм, и квалифицированный монизм Рамануджи, что пытается установить гармонию между абсолютизмом и личным теизмом. Все трое были великими мыслителями и реформаторами, чьи идеи прочно вошли в сознание индийской нации и вдохновляли как святых, так и простых людей [8].

Мыслитель Шанкара возвышался как колосс над всей страной, возрождая забытую прежде истину. Его философия абсолютного монизма является самой всеобъемлющей и наименее эксклюзивной. Это не ханжеская система, восхваляющая саму себя и осуждающая другие веры. Она построена на центральном принципе Упанишад, облагораживающем, коррективном и смелом.
Таким образом, разные люди в разное время вносили свою мудрость в непрерывное развитие индийской мысли, придавая свою форму силе индийского духа. Чтобы понять эффект индийской духовной культуры на жизнь индивидуума и общины, следует снова подчеркнуть ее синтезный характер и всеобъемлющее единение.

Фундаментальным представлением индийской духовности является единство существования Упанишад. Более того, Индия - это страна, где поиск, процесс становления представляет собой упорное движение в сторону познания сущности, истины, дающей смысл и цель всем вековым усилиям ее мыслителей.

«Как легкая роса, выпадающая невидимо и неслышимо, но помогающая расцвести цветам, - писал Свами Вивекананда, - таким является вклад Индии. Тихий и незаметный, однако по своему эффекту всеобъемлющий, он революционизировал мышление мира».

\section{ЛИТЕРАТУРА}

1. Keith A.B. The Religion and Philosophy of the Veda and Upanishads, Half. 1-2, Harvard University Press, 1925. - xix, 312 p. - (The Harvard Oriental Series Vol. 31).

2. Birch, J. The Amaraughaprabodha: New Evidence on the Manuscript Transmission of an Early Work on Hațha- and Rājayoga. Journal of Indian Philosophy, 47 (2019): 947-977. Springer.

3. Flood, Gavin D. An introduction to Hinduism. New York, NY : Cambridge University Press, 1996. - xviii, 341 p.

4. S.Radhakrishnan. Indian Philosophy, vol. I.L., 1927 (M., 1956). URL: http://psylib.org.ua/books/radha01/

5. Jamal Malik/ Helmut Reifeld (eds.), Religious Pluralism in South Asia and Europe. New Delhi: Oxford University Press, 2005. 317 p.

6. Карамазов В.Д. Всеобщая история религий мира. - Москва: Астрель ; Санкт-Петербург: Полигон, 2011. - 703 с.

7. Аникеева Е.Н. Бхагавадгита // Православная энциклопедия. - М.: Церковно-научный центр «Православная энциклопедия», 2003. - T. VI. - С. $408-409$.

8. К Костюченко В.С. Классическая веданта и неоведантизм : диссертация ... доктора философских наук : 09.00.03 / МГУ им. М.В. Ломоносова. - Москва, 1987. -408 c.

(c) Матвиенко Валентин Викторович (matvienko-vv@rudn.ru). 